\title{
Monitoring colonoscopy withdrawal time significantly improves the adenoma detection rate and the per- formance of endoscopists
}

Authors

Institutions

Corresponding author

Stephan R. Vavricka, MD

Division of Gastroenterology

and Hepatology

Triemli Hospital

Birmensdorferstrasse 497

CH-8063 Zurich

Switzerland

Fax: +41-44-4163301

stephan.vavricka@usz.ch

Stephan R. Vavricka1,2, *, Michael C. Sulz ${ }^{2, *}$, Lukas Degen ${ }^{3}$, Roman Rechner $^{2}$, Michael Manz $^{4}$, Luc Biedermann², Christoph Beglinger ${ }^{3}$, Shajan Peter $^{3}$, Ekaterina Safroneeva ${ }^{5}$, Gerhard Rogler $^{2}$, Alain M. Schoepfer

Institutions are listed at end of article.

Background and study aims: The recommended minimum withdrawal time for screening colonoscopy is 6 minutes. Adenoma detection rates (ADRs) increase with longer withdrawal times. We aimed to compare withdrawal times and ADRs of endoscopists unaware of being monitored vs. aware.

Patients and methods: Seven experienced gastroenterologists prospectively performed 558 screening colonoscopies during a 9-month period in a Swiss University hospital. Colonoscopy withdrawal times were first measured without the gastroenterologists' knowledge of being monitored ( $n=355$ colonoscopies) and then with their knowledge ( $\mathrm{n}=203$ colonoscopies).

Results: The median withdrawal time when gastroenterologists were unaware of being monitored was 4.5 minutes (interquartile range [IQR] 4-5.5 minutes) without intervention and 6 minutes (IQR 4-9 minutes) with intervention, increasing significantly to 7.3 minutes (IQR 6.5-9

\section{Introduction}

$\nabla$

Screening for colorectal cancer (CRC) is currently being or has been introduced in many countries in Europe [1]. In the last decade, colonoscopy has emerged as the most effective CRC screening strategy [2-5] preventing approximately $80 \%$ of CRCs $[6,7]$. However, colonoscopy has inherent limitations and its performance with a high level of quality is of crucial importance.

The European Society of Gastrointestinal Endoscopy (ESGE) recommends that national boards should monitor quality indicators and use them to license individual colonoscopists and endoscopy units [8]. Such quality indicators include, among others, bowel cleansing, cecal intubation rate, detection rate of adenomas and cancers, withdrawal time, retrieval rate of polyps, and re-

${ }^{*}$ The first two authors contributed equally to this article. minutes) and 8 minutes (IQR 7-11 minutes), respectively, when they were aware of being monitored $(P<0.001$ both for colonoscopies with and without intervention). The ADR increased from $21.4 \%$ when the gastroenterologists were unaware of being monitored to $36.0 \%$ when they were aware $(P<0.001)$. In the multivariate regression model, the endoscopists knowing they were being monitored was the strongest factor associated with ADR (odds ratio 4.417; 95\% confidence interval $[\mathrm{CI}] 2.241-8.705 ; P<0.001$ ).

Conclusions: Colonoscopy withdrawal time in unmonitored gastroenterologists is shorter than recommended and increases with awareness of monitoring. ADR significantly increases when gastroenterologists are aware of being monitored. Implementation of systematic monitoring, and analysis of withdrawal time and ADR for each endoscopist may help to increase the ADR.

cording of early and late adverse outcomes, such as perforations and bleeding [8]. Withdrawal time is defined as the length of time the colonoscopist spends withdrawing the colonoscope from the cecal pole to the anus. It is during this phase of the examination that detailed mucosal inspection for adenomas takes place. Withdrawal time has been particularly associated with polyp detection [9-13].

Two large studies have supported a minimum withdrawal time of 6 minutes in diagnostic colonoscopies without interventions such as polyp retrieval [9,11]. Barclay et al. [9] showed a threefold difference (9.4\% to $32.7 \%$ ) in adenoma detection rate (ADR) depending on the duration of withdrawal (which ranged from 3.1 to 16.8 minutes). Colonoscopists with withdrawal times longer than 6 minutes had higher detection of any neoplasia ( $28.3 \%$ vs. $11.8 \%$ ). Another and more recent analysis of the British CRC screening program 
showed that withdrawal times of 10 minutes were associated with the best ADR [14]. Therefore, the ESGE recommends a colonoscopy withdrawal time of at least 6 minutes, and gastroenterologists should increase their efforts to fulfil this goal. One method of achieving this goal is to actively monitor the withdrawal time; however, it is unknown whether this really increases the withdrawal time and also the ADR.

The aim of our study was to monitor the withdrawal time in two distinctly different preconditions: with or without endoscopists' knowledge that their withdrawal times were being monitored. We hypothesized that the mean withdrawal time of gastroenterologists who were unaware of being monitored would be shorter than recommended and that the same gastroenterologists, when they were aware of being monitored, would increase their withdrawal time. We further hypothesized that a longer withdrawal time would lead to an increase in the ADR. Finally, we aimed to investigate the gastroenterologists' accuracy in estimating their own withdrawal time.

\section{Patients and methods \\ $\nabla$}

\section{Patients}

During a 9-month period, outpatients referred for CRC screening colonoscopy to the Division of Gastroenterology and Hepatology of the University Hospital of Basel, Switzerland, a tertiary referral center, were prospectively included in this trial. The following inclusion criteria were applied: age > 18 years, referral for screening colonoscopy, and written informed consent provided. Patients were excluded if they fulfilled one or several of the following criteria: hospital inpatients, insufficient bowel preparation (according to Froehlich et al. [15]), previous colorectal surgery, or missing informed consent for colonoscopy.

Seven experienced gastroenterologists (each having undertaken $>500$ colonoscopies) performed the screening colonoscopies using Olympus EVIS EXERA II 180 series with high definition technology (Olympus, Tokyo, Japan). The type of endoscope (e.g. standard colonoscope, pediatric colonoscope) was chosen by the endoscopist. White-light endoscopy was used, and contrast dye was not routinely applied during colonoscopy. Withdrawal was performed by the endoscopist.

Bowel preparation was achieved using polyethylene glycol (Macrogol; Norgine, Amsterdam, The Netherlands), with $3 \mathrm{~L}$ administered on the night prior to the procedure, followed by another liter in the morning of the procedure. The procedures were performed with the patients under conscious sedation using nonanesthesiologist-administered propofol (AstraZeneca AG, Zug, Switzerland). Patients with multiple morbidities and/or American Society of Anesthesiologists (ASA) classification III/IV were evaluated by anesthesiologists who decided whether to perform the procedure with monitored anesthesia care or general anesthesia.

\section{Methods}

$\nabla$

In the first phase of this study, withdrawal time was monitored by an endoscopy nurse who was aware of the study, without the endoscopists knowing that they were being monitored. The endoscopists were not informed about the study until the first part was completed. Withdrawal time was measured as exact time in minutes and seconds. The endoscopy nurses were trained to deal with measuring the withdrawal time using a stopwatch without attracting the endoscopist's attention. During this part of the study, the measured withdrawal time was not documented on the usual report form, but was instead recorded on a separate sheet that was not given to the endoscopist.

During the second phase of the study, the same endoscopists were informed that the withdrawal time was going to be monitored. In addition, the endoscopist was required to estimate his own withdrawal time after each colonoscopy.

The time periods of both study phases were predefined (each 4.5 months), and once the time period for the first phase of the study was over, the second phase of the study began.

The patient characteristics, the quality of bowel cleansing, and the ADR were recorded. Cleansing quality was characterized according to the study of Froehlich et al., where colon cleansing was assessed by the endoscopist, on a 5-point scale: high cleansing quality, completely clean (score 5); clear liquid present (score 4); liquid plus solid stool present that can be aspirated (score 3); liquid and solid stool present that cannot be totally aspirated (score 2); or solid stool preventing visualization (score 1) [15]. A standardized procedure of polyp retrieval was used: polyps up to a size of $5 \mathrm{~mm}$ were removed by biopsy forceps and, for those > $5 \mathrm{~mm}$, an electrical snare was used after submucosal injection with 1:10 000 diluted adrenaline in saline. Data regarding the specific histologic type of adenoma (e.g. sessile serrated adenoma, tubulovillous adenoma, tubular adenoma) were not collected, except for a diagnosis of cancer.

This study was part of a quality audit program at the hospital. It was approved by the local Ethics committee.

\section{Statistical analysis}

The data were entered into a database (Microsoft Access 2000). All statistical analyses were performed with a statistical program (STATA, Version 12, College Station, Texas, USA). Data distribution was analyzed using the Shapiro-Wilk test for normal distribution. Results of quantitative data are presented as either mean \pm standard deviation (SD) and range for parametric data (referring to data with Gaussian distribution) or median plus interquartile range (IQR) for non-parametric data. Categorical data were summarized as the percentage of the total group.

Differences in quantitative data distributions were assessed by the Student's $t$ test (for parametric data), and the Mann-Whitney and Wilcoxon rank sum tests (for non-parametric data). A P value of $<0.05$ was considered statistically significant. A Bonferroni correction was performed where multiple testing was undertaken.

We performed binary logistic regression with "adenoma detection" as a binary dependent variable and multinomial logistic regression with "withdrawal time" (once without, and once with intervention) as continuous dependent variables. The analyses were performed with STATA v12. First the independent variables (monitoring Yes/No, number of endoscopists, sex (male vs. female), age of patients (continuous outcome in years), and bowel preparation (categorical outcome) were entered one by one into the logistic regression. Variables with a $P$ value $<0.1$ were then entered into the multivariate logistic regression model. 


\section{Results}

$\nabla$

\section{Baseline characteristics}

A total of 590 patients were screened of whom 27 were excluded because of poor bowel preparation, three because of previous colorectal surgery, and two because their records of informed consent were missing. Therefore, 558 patients were included in phases one and two. During the first phase of the study in which gastroenterologists were unaware of the withdrawal time being monitored, 355 patients underwent a screening colonoscopy. In the second phase of the study, when the gastroenterologists knew they were being monitored, 203 patients were recruited. The patient characteristics of all 558 patients are shown in $\bullet$ Table 1.

The quality of colon cleansing was as follows: poor, $\mathrm{n}=0$ patients (0\%); substandard, $n=24$ (4.3\%); adequate, $n=48$ (8.6\%); good, $n$ $=470(84.2 \%)$; and very good, $n=16(2.9 \%)$. Cleansing did not significantly differ in the two parts of the study.

The number of endoscopies performed per endoscopist were as follows: endoscopist \#1, 129 colonoscopies (23.1\%); endoscopist \#2, 102 colonoscopies (18.2\%); endoscopist \#3, 79 colonoscopies (14.2\%); endoscopist \#4, 72 colonoscopies (12.9\%); endoscopist \#5, 68 colonoscopies (12.2\%); endoscopist \#6, 63 colonoscopies (11.3\%); endoscopist \#7, 45 colonoscopies (8.1\%). A total of six CRCs were detected in the 558 patients (1.1\%). Mean polyp size was $7 \pm 6 \mathrm{~mm}$ (range $2-35 \mathrm{~mm}$ ).

\section{Withdrawal times when endoscopists were unaware of being monitored}

A total of 355 patients were included for the first phase of the study. We detected significant variations in the withdrawal time among different gastroenterologists $(P<0.001)$, both for colonoscopies without and with intervention. The median colonoscopy withdrawal times without intervention and with intervention in the first part of the study were 4.5 minutes (IQR 4 5.5 minutes) and 6 minutes (IQR $4-9$ minutes), respectively $(P<$ 0.001 ) ( Fig. 1). The proportion of colonoscopies without interventions that had a withdrawal time $<6$ minutes was $85.3 \%$ ( $\bullet$ Fig. 1).
Table 1 Characteristics of the patients undergoing screening colonoscopy in the two phases of the study.

\begin{tabular}{|llll|}
\hline & Phase 1 & Phase 2 & P value \\
\hline Number of patients & 355 & 203 & NA \\
\hline $\begin{array}{l}\text { Sex, male, } \mathrm{n}(\%) \\
\begin{array}{l}\text { Median age at colonoscopy, } \\
\text { years }\end{array}\end{array}$ & $196(55.2)$ & $93(45.8)$ & 0.037 \\
\hline \begin{tabular}{l} 
Cecal intubation rate, \% \\
\hline
\end{tabular} & $100 \%$ & 60.1 & 0.998 \\
\hline
\end{tabular}

NA, not applicable.

\section{Withdrawal times when endoscopists were aware of being monitored}

In the second phase of the study, gastroenterologists were informed that the withdrawal time was being monitored by the endoscopy nurse during the colonoscopy. A total of 203 patients (93 men [45.8\%]) were recruited and underwent colonoscopy during this phase.

The median colonoscopy withdrawal time without intervention was 7.3 minutes (IQR 6.5-9 minutes) compared with 8 minutes (IQR 7-11 minutes) for those including polypectomies $(P<$ 0.001 ). The endoscopists' estimated median colonoscopy withdrawal times without and with intervention were 7 minutes (IQR 6-8 minutes) and 8 minutes (IQR 7-10 minutes), respectively $(P<0.001)$.

Compared with the first phase of the study, we observed that the median objectively measured colonoscopy withdrawal time significantly increased in colonoscopies both without and with interventions when endoscopists were made aware of withdrawal time monitoring (increase of 2.8 minutes and 2 minutes in the groups without and with intervention, respectively; $P<0.001$ ). The proportion of colonoscopies without interventions that had a withdrawal time $<6$ minutes decreased to $13 \%$.

Comparing the objectively measured withdrawal times with those that were subjectively estimated for colonoscopies without intervention, we found that the objective median withdrawal time was not significantly different from the subjectively estimated median withdrawal time (7.3 minutes [6.5-9 minutes] vs. 7

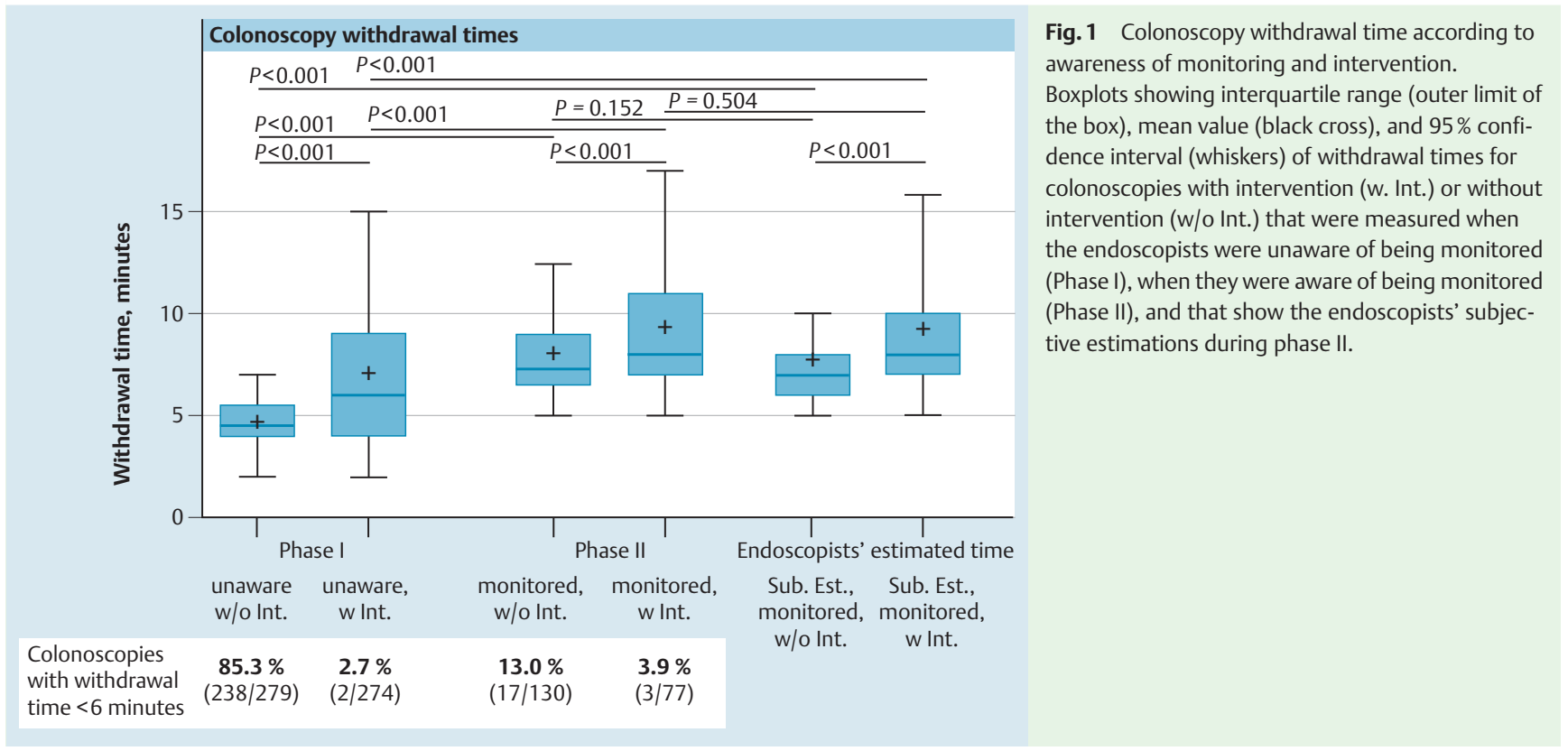




\begin{tabular}{|c|c|c|c|c|}
\hline \multicolumn{5}{|c|}{ Continuous outcome "withdrawal time without intervention" } \\
\hline & \multicolumn{2}{|c|}{ Univariate model } & \multicolumn{2}{|c|}{ Multivariate model } \\
\hline & $\begin{array}{l}\text { Odds ratio } \\
\text { (95\%CL) }\end{array}$ & $P$ value & $\begin{array}{l}\text { Odds ratio } \\
\text { (95\%CL) }\end{array}$ & $P$ value \\
\hline Adenoma detection & $\begin{array}{l}1.822 \\
(1.337,2.306)\end{array}$ & $<0.001$ & $\begin{array}{l}0.604 \\
(0.004,1.212)\end{array}$ & 0.051 \\
\hline Number of polyps & $\begin{array}{l}0.641 \\
(0.449,0.834)\end{array}$ & $<0.001$ & $\begin{array}{l}0.335 \\
(0.098,0.572)\end{array}$ & 0.006 \\
\hline Endoscopists & $\begin{array}{l}-0.249 \\
(-0.354,0.144)\end{array}$ & $<0.001$ & $\begin{array}{l}-0.012 \\
(-0.097,0.073)\end{array}$ & 0.785 \\
\hline Patient sex, male & $\begin{array}{l}-0.149 \\
(-0.597,0.299)\end{array}$ & 0.513 & - & \\
\hline Patient age, years & $\begin{array}{l}0.007 \\
(-0.008,0.214)\end{array}$ & 0.363 & - & \\
\hline Bowel preparation & $\begin{array}{l}0.242 \\
(-0.193,0.676)\end{array}$ & 0.276 & - & \\
\hline Awareness of monitoring & $\begin{array}{l}3.421 \\
(3.051,3.791)\end{array}$ & $<0.001$ & $\begin{array}{l}3.250 \\
(2.876,3.624)\end{array}$ & $<0.001$ \\
\hline
\end{tabular}

Table 2 Linear regression model for withdrawal time for colonoscopies without intervention.

$95 \% \mathrm{CL}, 95 \%$ confidence limits.

\begin{tabular}{|c|c|c|c|c|}
\hline & \multicolumn{2}{|l|}{ Univariate model } & \multicolumn{2}{|c|}{ Multivariate model } \\
\hline & $\begin{array}{l}\text { Odds ratio } \\
\text { (95\%CL) }\end{array}$ & $P$ value & $\begin{array}{l}\text { Odds ratio } \\
\text { (95\%CL) }\end{array}$ & $P$ value \\
\hline Adenoma detection & $\begin{array}{l}4.768 \\
(4.113,5.423)\end{array}$ & $<0.001$ & $\begin{array}{l}2.161 \\
(1.182,3.139)\end{array}$ & $<0.001$ \\
\hline Number of polyps & $\begin{array}{l}1.907 \\
(1.651,2.163)\end{array}$ & $<0.001$ & $\begin{array}{l}1.196 \\
(0.816,1.577)\end{array}$ & $<0.001$ \\
\hline Endoscopists & $\begin{array}{l}-0.220 \\
(-0.381,0.059)\end{array}$ & 0.007 & $\begin{array}{l}-0.001 \\
(-0.138,0.135)\end{array}$ & 0.984 \\
\hline Patient sex, male & $\begin{array}{l}0.296 \\
(-0.381,0.974)\end{array}$ & 0.391 & - & \\
\hline Patient age, years & $\begin{array}{l}0.021 \\
(-0.001,0.043)\end{array}$ & 0.065 & $\begin{array}{l}-0.002 \\
(0.020,0.159)\end{array}$ & 0.810 \\
\hline Bowel preparation & $\begin{array}{l}0.283 \\
(-0.373,0.939)\end{array}$ & 0.398 & - & \\
\hline Awareness of monitoring & $\begin{array}{l}2.249 \\
(1.569,2.928)\end{array}$ & $<0.001$ & $\begin{array}{l}1.687 \\
(1.087,2.287)\end{array}$ & $<0.001$ \\
\hline
\end{tabular}

Table 3 Linear regression model for withdrawal time for colonoscopies with intervention.

95\%CL, $95 \%$ confidence limits.

minutes [6- 8 minutes]; $P=0.152$ ). Similarly, the objective median withdrawal time for colonoscopies including interventions was not statistically different from the subjectively estimated median withdrawal time ( 8 minutes [7-11 minutes] vs. 8 minutes [7-10 minutes]; $P=0.504)$. These different time intervals are illustrated in $\bullet$ Fig. 1.

\section{Linear regression model for withdrawal time}

The linear regression model for withdrawal time showed that for "withdrawal time without intervention" the fact that the endoscopist was aware of being monitored strongly positively influenced the withdrawal time (odds ratio [OR] 3.250, 95\% confidence interval $[\mathrm{CI}] 2.876-3.624 ; P<0.001 ; 0$ Table 2). We found that for the length of the "withdrawal time with intervention" the following factors were positively associated in the multivariate analysis: adenoma detection, number of polyps, and the fact that the endoscopist was aware of being monitored ( $\bullet$ Table 3 ).

\section{Adenoma detection rate increases with longer} colonoscopy withdrawal time

In the first phase of this study, adenomas were detected in 76 out of 355 patients, giving a calculated ADR of $21.4 \%$. In the second phase of the study, adenomas were found in 73 out of 203 patients, giving a calculated ADR of $36.0 \%$. This increase was statistically significant $(P<0.001 ; 0$ Fig. 2$)$.

\section{Univariate and multivariate logistic regression model} for the outcome "adenoma detection"

In the multivariate model, the endoscopist being aware of monitoring was the strongest factor associated with adenoma detection (OR 4.417; $P<0.001$ ). Male sex was not significantly associated with adenoma detection. Details are shown in $\bullet$ Table 4. 


\begin{tabular}{|c|c|c|c|c|}
\hline \multicolumn{5}{|c|}{ Binary outcome "adenoma detection" (yes vs. no) } \\
\hline & \multicolumn{2}{|c|}{ Univariate model } & \multicolumn{2}{|c|}{ Multivariate model } \\
\hline & $\begin{array}{l}\text { Odds ratio } \\
\text { (95\%CI) }\end{array}$ & $P$ value & $\begin{array}{l}\text { Odds ratio } \\
\text { (95\%Cl) }\end{array}$ & $P$ value \\
\hline \multicolumn{5}{|l|}{ Awareness of monitoring } \\
\hline $\begin{array}{l}\text { Yes } \\
\text { No }\end{array}$ & $\begin{array}{l}2.061 \\
(1.406-3.022) \\
\text { Reference }\end{array}$ & $<0.001$ & $\begin{array}{l}4.417 \\
(2.241-8.705)\end{array}$ & $<0.001$ \\
\hline Endoscopists & $\begin{array}{l}0.885 \\
(0.809-0.969)\end{array}$ & 0.008 & $\begin{array}{l}0.925 \\
(0.819-1.042)\end{array}$ & 0.201 \\
\hline \multicolumn{5}{|l|}{ Patient sex } \\
\hline $\begin{array}{l}\text { Male } \\
\text { Female }\end{array}$ & $\begin{array}{l}1.461 \\
(0.999-2.138) \\
\text { Reference }\end{array}$ & 0.051 & $\begin{array}{l}1.402 \\
(0.871-2.258)\end{array}$ & 0.164 \\
\hline Patient age, years & $\begin{array}{l}1.026 \\
(1.012-1.039)\end{array}$ & $<0.001$ & $\begin{array}{l}1.024 \\
(1.008-1.041)\end{array}$ & 0.003 \\
\hline Bowel preparation & $\begin{array}{l}0.779 \\
(0.551-1.102)\end{array}$ & 0.159 & - & \\
\hline $\begin{array}{l}\text { Withdrawal time for colonos- } \\
\text { copies without intervention }\end{array}$ & $\begin{array}{l}1.291 \\
(1.193-1.397)\end{array}$ & $<0.001$ & $\begin{array}{l}0.614 \\
(0.514-0.733)\end{array}$ & $<0.001$ \\
\hline $\begin{array}{l}\text { Withdrawal time for colonos- } \\
\text { copies with intervention }\end{array}$ & $\begin{array}{l}1.431 \\
(1.333-1.436)\end{array}$ & $<0.001$ & $\begin{array}{l}1.799 \\
(1.583-2.045)\end{array}$ & $<0.001$ \\
\hline
\end{tabular}

Table 4 Univariate and multivariate logistic regression model for the outcome "adenoma detection."

$95 \% \mathrm{Cl}, 95 \%$ confidence interval.

\section{Discussion \\ $\nabla$}

The performance of colonoscopies with a high level of quality is regarded as an effective strategy to reduce CRC-associated morbidity and mortality. Indicators of quality in colonoscopy include various items, such as cecal intubation rate, adequate colon cleansing, and a minimum withdrawal time from the cecum backwards of 6 minutes [16]. The withdrawal time is fully operator dependent.

Our study adds novel and clinically relevant insights to this topic of the quality aspects of colonoscopy. Whereas previous studies of withdrawal techniques and ADR have always focused on physicians who were aware of being monitored $[9,11,12]$, in this study we show for the first time our results with regard to withdrawal time in endoscopists who were unaware that they were being monitored. Obviously, the endoscopists' practice regarding withdrawal time is strongly influenced by his/her knowledge of being monitored. With $85.3 \%$ of colonoscopies without intervention having a withdrawal time $<6$ minutes, we found that the endoscopists' adherence to the recommended withdrawal time of at least 6 minutes was very low in a "real-world setting," meaning when they were unaware that their withdrawal time was being monitored.

Low adherence to the recommended withdrawal time seems to be of concern. Butterly et al. [17] demonstrated that nearly a quarter of endoscopists had median withdrawal times (without interventions) of 6 minutes or less. Our data further support the findings of Barclay et al. [18] who showed that using a timer to assist colonoscopists can lengthen the withdrawal time and improve ADR. Sawhney et al. [19] reported that recording of the exact withdrawal time at the end of the procedure by the endoscopy nurse and reporting compliance rates to colonoscopists can improve compliance with a 7-minute withdrawal time from $65 \%$ to almost $100 \%$. Similarly, Sinn et al. [20] found that formal documentation of withdrawal time forced endoscopists to lengthen their withdrawal time. We conclude that endoscopists' know- ledge that a quality measure is being monitored represents a powerful tool that can in itself increase the quality of colonoscopy.

We found that ADR significantly increased with the endoscopists' knowledge of being monitored with regard to withdrawal time. The positive association between withdrawal time and ADR has been shown by other studies [14,17]. Both of these studies showed a statistically significant correlation between longer withdrawal time and higher ADR, peaking at 9 minutes. Butterly et al. [17] demonstrated the benefit of longer withdrawal time for serrated polyps too, defined as sessile serrated adenoma and hyperplastic polyps proximal to the sigmoid colon. When modeling was used in that study, it was determined that setting the minimum withdrawal time at 9 minutes would result in adenoma and serrated polyps being detected in $3.8 \%$ and $2.4 \%$ more patients (relative increase of $30 \%$ ). More importantly, the increase in ADR has been shown to directly translate into a decrease in inter-

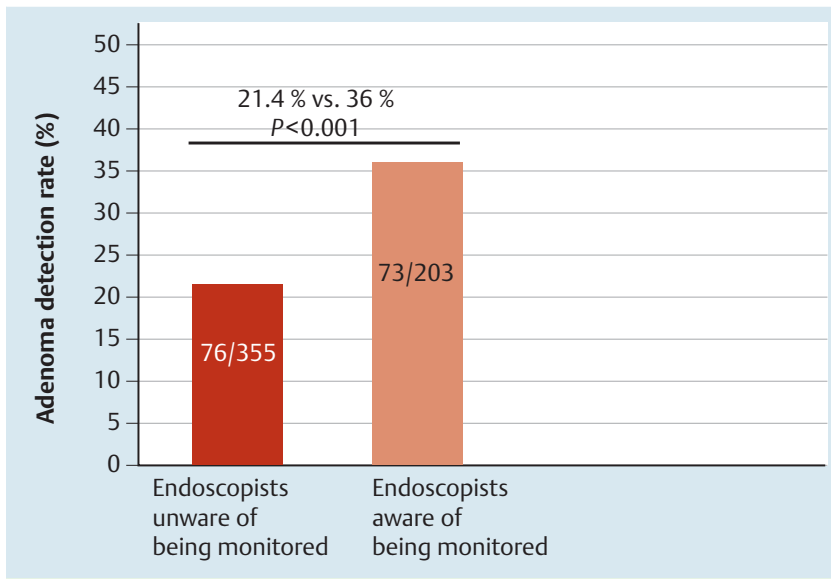

Fig.2 Adenoma detection rate (ADR) in the two phases of the study. The increase in ADR was statistically significant $(P<0.001)$. 
val CRCs [21,22]. Therefore, such a simple and easily implementable intervention as standardized monitoring of withdrawal time within gastroenterology units may ultimately prevent numerous cancer deaths.

Our study has several strengths and some limitations as well. The major strength is that this study represents the first time a clear and unbiased change in endoscopists' habits before and after being made aware that their withdrawal times were being monitored. When they knew that the withdrawal time was being measured and documented, the endoscopists obviously placed more attention on the quality of the colonoscopy and performed a more meticulous examination. This phenomenon is also known as the Hawthorne effect. During observational studies in the $1920 \mathrm{~s}$ in the Hawthorne Western Electric Company, Chicago, USA, it was found that workers increased their productivity when they knew that they were observed in a study. As a consequence of this effect, ADR significantly increased; however, we were unable to show whether this was an ongoing effect over a longer period of time. An additional strength was that the prospective assessment reduced potential bias.

Some limitations should be discussed as well. First, withdrawal technique may be more important than withdrawal time [19, $23-26]$. We did not assess withdrawal techniques in our study. Among the elements comprising a decent withdrawal technique, vigilant observation, fold examination, and good colonic distension are to be mentioned; however, these parameters are much more difficult to monitor and quantify. Therefore, the duration of withdrawal may be a surrogate for an adequate withdrawal technique and indeed duration has served as such a proxy in the majority of trials investigating correlations between the modality of withdrawal and ADR. Presumably, maneuvers to improve mucosal inspection (which incidentally increases withdrawal time), such as repositioning the patient, adequate insufflation and suction, meticulous mucosal re-inspection, careful inspection of the proximal aspect of folds, and rectal retroversion, are performed more frequently by "good" colonoscopists, which ultimately leads to higher ADRs and longer withdrawal times. Further limitations are the absence of a long-term study period and a relatively low statistical power to assess differences between endoscopists.

Our study highlights the importance of measuring and documenting withdrawal time in everyday practice. The knowledge that colonoscopy withdrawal time is being measured results in endoscopists significantly increasing their withdrawal time and consequently detecting more polyps. When they are aware of being monitored, endoscopists were accurate in estimating the measured withdrawal time. Our data indicate that simply monitoring and documenting withdrawal time can improve the quality of colonoscopy in daily practice and ultimately prevent interval cancer and cancer death.

\section{Acknowledgments}

This research was supported by grants from the Swiss National Science Foundation (SNF) to S.R.V. (Grant No.320000-114009/3 and 32473B_135694/1) and to A.M.S. (Grant No. 32003B_135665/1).

\section{Competing interests: None}

Institutions

${ }^{1}$ Division of Gastroenterology and Hepatology, Triemlispital, Zurich, Switzerland

${ }^{2}$ Division of Gastroenterology and Hepatology, University Hospital Zurich, Switzerland

${ }^{3}$ Division of Gastroenterology and Hepatology, University Hospital Basel, Switzerland

${ }^{4}$ Division of Gastroenterology and Hepatology, Claraspital, Basel, Switzerland

${ }^{5}$ Institute of Social and Preventive Medicine, University of Bern, Switzerland

${ }^{6}$ Division of Gastroenterology and Hepatology, Centre Hospitaler Universitaire Vaudois/CHUV, Lausanne, Switzerland

\section{References}

1 Benson VS, Patnick J, Davies AK et al. International colorectal cancer screening network. Colorectal cancer screening: a comparison of 35 initiatives in 17 countries. Int J Cancer 2008; 122: 1357 - 1367

2 Seeff LC, Richards TB, Shapiro JA et al. How many endoscopies are performed for CRC screening? Results from CDC's survey of endoscopic capacity Gastroenterology 2004; 127: 1670-1677

3 Prajapati DN, Saeian K, Binion DG et al. Volume and yield of screening colonoscopy at a tertiary medical center after change in medicare reimbursement. Am J Gastroenterol 2003; 98: 194-199

4 Elmunzer BJ, Singal AG, Sussman J et al. Comparing the effectiveness of competing tests for reducing colorectal cancer mortality: a network meta-analysis. Gastrointest Endosc 2015; 81: 700-709

5 Brenner H, Stock C, Hoffmeister M. Effect of screening sigmoidoscopy and screening colonoscopy on colorectal cancer incidence and mortality: systematic review and meta-analysis of randomised controlled trials and observational studies. BMJ 2014; 348: g2467 DOI 10.1136/ bmj.g2467

6 Winawer SJ, Zauber AG, Ho MN et al. Prevention of CRC by colonoscopic polypectomy. NEJM 1993; 329: $1977-1981$

7 Citards F, Tomaselli G, Capocaccia $R$ et al. Efficacy in standard clinical practice of colonoscopic polypectomy in reducing colorectal cancer incidence. Gut 2001; 48: 812-815

8 Rembacken B, Hassan C, Riemann JF et al. Quality screening colonoscopy: position statement of the European Society of Gastrointestinal Endoscopy (ESGE). Endoscopy 2012; 44: 957 -968

9 Barclay RL, Vicari JJ, Doughty AS et al. Colonoscopic withdrawal times and adenoma detection during screening colonoscopy. NEJM 2006; 355: $2533-2541$

10 Overholt BF, Brooks-Belli L, Grace M et al. Withdrawal times and associated factors in colonoscopy: a quality assurance multicenter assessment. J Clin Gastroenterol 2010; 44: e80 - e86

11 Simmons DT, Harewood GC, Baron TH et al. Impact of endoscopist withdrawal speed on polyp yield: implications for optimal colonoscopy withdrawal time. Aliment Pharmacol Ther 2006; 24: 965 -971

12 Sanchez W, Harewood GC, Petersen BT. Evaluation of polyp detection in relation to procedure time of screening or surveillance colonoscopy. Am J Gastroenterol 2004; 99: 1941 - 1945

13 Fatima $H$, Rex $D K$, Rothstein $R$ et al. Cecal insertion and withdrawal times with wide-angle versus standard colonoscopes: a randomized controlled trial. Clin Gastroenterol Hepatol 2008; 6: 109-114

14 Lee TJW, Blanks RG, Rees CJ et al. Colonoscopy quality measures: experience from the NHS Bowel Cancer Screening Programme. Gut 2012; 61: 1050 - 1057

15 Froehlich F, Wietlisbach V, Gonvers J-J et al. Impact of colonic cleansing on quality and diagnostic yield of colonoscopy: the European Panel of Appropriateness of Gastrointestinal Endoscopy European multicenter study. Gastrointest Endosc 2005; 61: 378-384

16 Rex DK, Bond JH, Winawer S et al. Quality in the technical performance of colonoscopy and the continuous quality improvement process for colonoscopy: recommendations of the U.S. Multi-Society Task Force on Colorectal Cancer. Am J Gastroenterol 2002; 97: 1296-1308

17 Butterly L, Robinson CM, Anderson JC et al. Serrated and adenomatous polyp detection increases with longer withdrawal time: results from the New Hampshire Colonoscopy Registry. Am J Gastroenterol 2014; 109: $417-426$

18 Barclay RL, Vicari JJ, Greenlaw RL. Effect of a time-dependent colonoscopic withdrawal protocol on adenoma detection during screening colonoscopy. Clin Gastroenterol Hepatol 2008; 6: 1091 -1098

19 Sawhney MS, Cury MS, Neeman N et al. Effect of institution-wide policy of colonoscopy withdrawal time $>$ or $=7$ minutes on polyp detection. Gastroenterology 2008; 135: $1892-1898$ 
20 Sinn DH, Chang DK, Choi WS et al. Formal documentation of withdrawal time to improve the quality of colonoscopic observation. Hepatogastroenterology 2011; 58: 779-784

21 Lee TJ, Blanks RG, Rees CJ et al. Longer mean colonoscopy withdrawal time is associated with increased adenoma detection: evidence from the Bowel Cancer Screening Programme in England. Endoscopy 2013; 45: $20-26$

22 Kaminski MF, Regula J, Kraszewska E et al. Quality indicators for colonoscopy and the risk of interval cancer. NEJM 2010; 362: 1795-1803
23 Corley DA, Jensen CD, Marks AR et al. Adenoma detection rate and risk of colorectal cancer and death. NEJM 2014; 370: 1298-1306

24 Lee RH, Tang RS, Muthusamy VR et al. Quality of colonoscopy withdrawal technique and variability in adenoma detection rates. Gastrointest Endosc 2011; 74: 128 - 134

25 Rex DK. Colonoscopic withdrawal technique is associated with adenoma miss rates. Gastrointest Endosc 2000; 51: 33-36

26 Rex DK, Hewett DG, Raghavendra $M$ et al. The impact of videorecording on the quality of colonoscopy performance: a pilot study. Am J Gastroenterol 2010; 105: 2312-2317 